conducted to assess the quality of directly observed treatment of tuberculosis in Dhaka city to enhance Stop TB strategy supported by National Tuberculosis Programme (NTP), Bangladesh.

Methods Data were collected from 11 DOT centers located in 11 out of 90 wards in Dhaka city using a two-stage systematic sampling technique. All the facilities providing DOT services were the primary sampling unit for this study. A total of 62 pulmonary tuberculosis cases selected were interviewed at home.

Results Mean ages of the patients were $31 \pm 12$ years, $61.3 \%$ were male and $84 \%$ literate. About $95 \%$ patients gave 3 sputum samples whereas only $62 \%$ followed correct procedure for giving sputum for diagnosis. $73 \%$ of the patients swallowed drug at home. About $74 \%$ respondents swallowed drug under direct observation. Treatment follow-up schedule was followed by $88 \%$ smear positive and $93 \%$ smear negative patients. Patients had highly positive attitude towards DOT though $58 \%$ of the patients showed average knowledge level regarding tuberculosis. Overall 78\% patients showed adherence to DOT. Level of education showed significant association $(p<0.05)$ with patients' "opinion about necessity of direct observation" and "following of sputum giving procedure correctly for diagnosis.

Conclusion Although patients level of knowledge was average but showed highly positive attitude and good adherence towards DOT. Strict monitoring, frequent sensitisation and assistance regarding diagnosis and treatment follow-up may increase the adherence as well as quality of DOT.

\section{SP3-72 FRUIT AND VEGETABLES INTAKE AND PLASMA HOMOCYSTEINE LEVELS AMONG RESIDENTS OF MUNICIPALITY OF SÃO PAULO}

doi:10.1136/jech.2011.1429760.72

R S Bigio,* M A de Castro, J Steluti, V T Baltar, R M Fisberg, D M L Marchioni. University of São Paulo, São Paulo, São Paulo, Brazil

Introduction The elevated concentration of plasma homocysteine ( $\mathrm{pHcy}$ ) was recently identified as risk factor for cardiovascular disease. Many studies have linked consumption of fruits and vegetables (F\&V) with decreased of pHcy.

Objectives To investigate the pHcy concentrations according to consumption of F\&V.

Methods A cross-sectional analysis was conducted in a sample of 291 individuals of both sexes, aged $12 \mathrm{y}$ or over, that are from a population-based study performed in 2008-2010 in municipality of São Paulo. The consumption of fruits and vegetables were measured by two 24-h dietary recalls applied in non-consecutive days. Biochemical analysis of pHcy was conducted by the fluorescence polarisation immunoassay method. The cut-off point of $\mathrm{pHcy}$ used was $<8 \mu \mathrm{mol} / 1$ for individuals younger than $15 \mathrm{y},<12 \mu \mathrm{mol} / 1$ for individuals with $15-65 \mathrm{y}$ and $<16 \mu \mathrm{mol} / \mathrm{l}$ for those over $65 \mathrm{y}$. The median consumption of F\&V was described according to the pHcy levels (normal or high) in both sexes and analysed using the Kruskal-Wallis test.

Results The median of F\&V was $97.9 \mathrm{~g} /$ day, with females exhibiting the higher consumption (134 g/day). Considering the WHO recommendation ( $>400 \mathrm{~g} /$ day), only $5.8 \%$ of individuals had adequate intake. There were no differences in the medians of intake of fruit and vegetables in females according to pHcy levels (normal: $112.88 \mathrm{~g} /$ day; high: $155.25 \mathrm{~g} /$ day). Unlike, we found lower consumption of $\mathrm{F} \& \mathrm{~V}$ in males with hyperhomocysteinemia (normal: $96.80 \mathrm{~g} /$ day; high: $23.30 \mathrm{~g} /$ day; $\mathrm{p}=0.01$ ).

Conclusion F\&V intake is low in this population, especially in men with hyperhomocysteinemia. Therefore, it is necessary to encourage the $\mathrm{F} \& \mathrm{~V}$ intake in this population.

\section{SP3-73 INCREASE OF RAILWAY SUICIDES IN GERMANY AFTER THE RAILWAY SUICIDE DEATH OF ROBERT ENKE, A FAMOUS GERMAN FOOTBALL PLAYER}

doi:10.1136/jech.2011.142976o.73

${ }^{1} \mathrm{~J}$ Baumert, ${ }^{1} \mathrm{~S}$ Kunrath, ${ }^{1,2} \mathrm{~K} \mathrm{H}$ Ladwig. ${ }^{1}$ Institute of Epidemiology II, Helmholtz Zentrum München, Neuherberg, Germany; ${ }^{2}$ Department of Psychosomatic Medicine and Psychotherapy, Klinikum rechts der Isar, Technische Universität München, Munich, Germany

Introduction Robert Enke, an internationally respected German football goal keeper committed railway suicide on the 10 November 2009. Concerns were raised about the potential of this event to spark copycat suicides afterwards. Therefore, we analysed the impact on the frequency of subsequent railway suicides.

Methods The daily incidence of railway suicides was derived from the Event Database Safety (EDS), the national database of person accidents on the German railway net. We compared the daily numbers of suicides from 11 November to 31 December in 2006-2009 and the number of suicides 28 days before and after the event by estimating incidence ratios with $95 \%$ CIs using Poisson regression.

Results The mean daily number of suicide acts in the critical time window in 2006 to 2008 was about 2 but almost 4 in 2009. The incidence ratio was 1.81 (95\% CI 1.48 to 2.21 ), thus showing a daily increase after Enke's suicide by $81 \%$ compared to the previous years. Comparison of the number of suicides 28 days before and after the incidence revealed similar results. No modifications of these associations were observed by daytime, by location of the suicide and death.

Conclusion The present study indicates that a celebrity suicide may bring about copycat behaviour in an unforeseen amount, even if the reporting in the media seems to be rather sensitive and other preventive measures are taken.

\section{SP3-74 EXPEDITED APPROACH TO DISSEMINATING EVIDENCE TO POLICY MAKERS IN ORDER TO IMPROVE ABORIGINAL CHILD HEALTH AND WELL-BEING IN CANADA}

doi:10.1136/jech.2011.142976o.74

${ }^{1,2,3}$ S Tough, ${ }^{* 1} \mathrm{~N}$ Reynolds, ${ }^{4} \mathrm{D}$ McNeil, ${ }^{5} \mathrm{~B}$ lahtail, ${ }^{4} \mathrm{~S}$ Rikhy. ${ }^{1}$ Alberta Centre for Child, Family and Community Research, Edmonton, Alberta, Canada; ${ }^{2}$ Department of Paediatrics, University of Calgary, Calgary, Alberta, Canada; ${ }^{3}$ Department of Community Health Sciences, University of Calgary, Calgary, Alberta, Canada; ${ }^{4}$ Public Health Innovation and Decision Support, Alberta Health Services, Calgary, Alberta, Canada; ${ }^{5}$ Creating Hope Society, Edmonton, Alberta, Canada

Objectives To facilitate timely uptake of research evidence by policy makers and support the implementation of evidence-informed policies and practices to improve Aboriginal child health and wellbeing.

Methods This work was initiated in response to national government interest in improving Aboriginal child health and well-being. The approach began with a synthesis review which critically and culturally appraised published papers to identify promising practices. Next, a summary of the synthesis and other relevant reports was written for stakeholders and five recommendations were developed. The research team and other researchers in the area validated these documents. Key stakeholders, including policy makers, community leaders, and content experts, were surveyed to assess general support for the recommendations, identify other key contacts, and identify facilitators and barriers to dissemination. With support from stakeholders and the lead organisation's board of directors, the recommendations were finalised as a brief "Call To 